the aid of the bandage, and by using great circumspection in my movements, to try to keep afoot. I put myself on limited regimen for a few days, but nothing more. For the first three days the calf continued considerably swollen, and was tender on pressure, but without actual pain, and no sign of inflammatory action. About the third day cousiderable discolouration appeared around the tender spot, and extended in a band, in a less marked degree, upwards in the line of tenderness along the inner margin of the tibia; there was occasionally the feeling of a lump or tightness in the popliteal space, which I accounted for by the attacliment of the plantaris to the posterior ligaments of the knee-joint. On these days I drove about the farm, and from the lanes occasionally got a shot at a driven partridge. Oa the fourth day I ventured into the fields, but found I could do little or nothing on rough ground, having absolutely no power of heel-and-toe walking. At the end of a week the swelling and tenderness had greatly subsided, but there was little corresponding improvement in walking. I then went to Scotland, and at the end of ten clear days found distinct improvement, and on the twelfth day actually began beeland-toe walking. From that time I gradually got better, although some days I was much stiffer and more lame than on others. At the end of three weeks I left off the bandage, but still had to walk very deliherately and with discretion, as any inadvertent throwing of weight on the toes at once caused a sort of wrench at the seat of injury. At the end of four weeks my walking on the level was almost the normal heel-and-toe, but on going up-and down-stairs the flat foot hid sill to be used. At the end of five weeks I felt little inconvenience, except at times a trifling stiffoess, generally of the calf, and at the end of six weeks full power had returned, at all events on the level, for I had not yet tried walking on rough ground.

It may be asked, Woat was the exact na'ure and seat of this injury? It was clearlv a rupture, probably both of mucle and firous tissue, but its exact seat is more difficult to fix. At first, from the loss of power over the toes, I thought the flexor longus pollicis was injured, but I soon saw this los 3 was apparent, not real, and arose from inability to raise the heel and so throw the weight forward on the toes. Then the injured structures clearly lay deeper than the gastrocnemius; and from the line of tenderness and discolouration, and especially from the peculiar sensations in the popliteal space, I think there is little doubt that the plantaris was torn, and the place of rupture was at the tender spot. Yet its is hard to understand that, if this diagnosis be correct, how the almost rudimentary planturis can exercise such an important function in walking. The rupture was entirely caused by nuscular effort, and brought abnut, I thiuk, by the sudden throwing of the weight on the left leg while the foot was fixed and the hody in a strained, half-turned position. Such an accident one would in trine, should be of frequent occurrence, vet it is really rare. 'This points to predisposing causes, which may be of an individual as well as a general kind. Age is ap. parently one (my own forty-seven); for the cases described seemed to have beon in middle-aged men, especially clergymen, who lead sedentary lives and get heavy in body; pro bably the fibrous structures become more rigid and brittle in middle life. Want of training and being out of hard condition wonld und oubterly predispose; aud I feel so certain of that, if it should be my fortune to shoot next year, I shall practise walking over rough ground for some time befo:e I venture on the moors or the stubb'e fields.

As to treatment, my case shows that absi.lute rest is not essential, yet I strongly advise it, as throughout I felt conscious of rlsk in moviug abuut, at all events in delaying cure. Of course, the injury is also one of degree, and may be so severe as to conpel complete rest. The unyielding bandige or strap was of first service; in fact, I could not have walkid at all without it ; it thoroughly tixsd and supported the calf. I tried an elastic stocking in place of ir, but it was not of the least use as an effective support. The uuion of the torn structures was evidently ravid, being by the tenth day tolerahly strong, but not reaching any degree of full strength till the fourth week. But the period of union or cure apparently varies much, for I bave heard of a case very siwilar to my own, in which the patient was crippled for six month. It seems, however, pretty certain that this is not an iojury that can be trifled witb, and that those who unfortunately suffer from it, to whatever extent or degree, should carefully abstain frow all violent muscular movements for months afterwards.

\section{AN UNUSUAL CASE OF PREGNANCY.}

\author{
BY H. M. FENWICK, M.B. DURH., L.R.C.P.ED., \&c.
}

I HAVE been induced to publish the following notes, not only because the case is unique in my own experience, but because I can find no mention of a similar one in any of the ordinary obstetric works.

Mrs. H_- aged twenty-four, secundipara, was seized with labour pains on July 20 th last, when living at $\mathrm{C}-$. Although she had not expected to bs confined until the middle of August, she felt as it she were going to be "put to bed" at onc?. Everything was got ready for the lying-in; al] her female friends were summoned, as is usual in this district; and then the medical man who had been engaged for the case was sent for. Meanwhile "the waters" had broken, the woman being immediately lifted into bed. On his arrival the doctor made the usual examination, gave his patient "a pill," and, after promising to effect delivery next morning, took his departure. The pains gradually left the woman, and after a day or two she got up and went about as usual, although much inconvenienced by a considerable watery discharge from the vagina. After an interval of a few days this was replaced by a slimy, bad-smelling discharge, which was still continuing to come away when Mrs. $\mathrm{H}-$ came to live in this village on August 6th. I was sent for next morning. After hearing her history I made a vauinal examination. I found the os uteri very high, and was unable to make much depression by downward pressure with the other hand on the abdominal wall over the fundus. I found that the os was very soft and cedematous, and dilated to abcut the size of a shilling. The finger after introduction into the os was found to be covered with a thick, stringy, tenacious, rather foul-smelling gelatinous substance. I was unable to get "ballottement;" on auscultation the fortal heart could not be heard, and the placental bruit was very indistinct. The abdomen was more than usually distended, and on palpation a sof c "boggy" feeling was experienced over almost its whole extent. The uterus and its contents were very difficult to define. At this time the woman was complainug of recurring rigors and "drenching sweats," pain iu the back, profuse diarrhoea, persistent vomiting, severe frontal headache, and total inappetency. Her skin was markedly icteric in hue, and her lower eyelids were congested and swollen. The temperature varied from $100^{\circ}$ to $101^{\circ} \mathrm{F}$. at night to slightly above normal in the moruing. The pulse aud respiration were also considerably accele. rated. I concluded the fotus was dead. On August $14 \mathrm{~h}$ I had a consultation on the case with Dr. Proudfoot of Newbigsin-by-Sea. He agreed with me that in all probability the child was drad. We then considered the expedieucy of inducing the expulsion of the uterine contents, but determived not to do so uuless the symptoms became more urgent. The next day as the fetor of the vayinal discharge was still troubling my patient, I plugged the vagina with a tampon of wool soaked in a weak glyc role of carbolic acid. From this time she improved wonderfully. The vomiting and diarrhoea which had resisted all treatment stopped; the rigors ceased, appetite was regained, and nothing was complained of until the evtuing of Sept. 3rd, when I was sent for. On arrival I found the woman in labour, the "pains" strong and regular. On examination I found the head coming through the brim in the first position. In the bed was a large quantity of ropy, thick mu ilagnous matter. After waiting two hours, as no progress was being made, although the os was fully di'ated, and, as the woman was becoming delirious, I put on Simpson's lung forceps and delivered her of a full grown, living, fernale child. The birth of the child was followed by the discharge of about a quart of the jelly.like matter before alluded io; and, together with. and atter the removal of, the placenta, which was adherent, I brought away about another quart. The mother recsvered rafidly, and both she and her child have done well since. I may state that at no time was there any albuminuria or codena of the ankles or legs. Microscopically, I could make out little in the jelly; a few delicate fibres and some small irregular crystalline bodies. On exposure to the air, the jelly rapidy liquefied, and in ten hours was like water. I give the case simply as it occurred, and make no attempt to acconnt for the presence of the large quantity of mucilaginous matter contained in the uterus.

The diagnosis that the foetus was dead was wrong; but 
without the knowledge of the record of a similar cass, it will be easily understood that the intervention of a thick layer of jelly-like matter between the foetus and the uterus would prevent transmission of the foetal heart-sounds th ough the uterine and abdominal walls; and if there be added to this the fact of the observance of several of the usual symptoms of foetal death, I think it will be acknowledged that I was fully justified in the diagnosis at which I arrived.

North Seaton, Northumberland.

\section{A 解tirut$$
\text { OF }
$$

\section{HOSPITAL PRACTICE, BRITISH AND FOREIGN.}

Nullaautemes $t$ alia procerto noscendivia, nisi quamplurimas et morborum otdiscectionum historias, tum aliorum tum proprias collectas habere, et

\section{MIDDLESEX HOSPITAL.}

GUNSHOT WOUND OF SKULT; LODGMENT OF BULLET IN BRAIN; TREPIINING; DEATH ON THE THIRTEENTH DAY.

(Under the care of Mr. George LAwson.)

For the notes of the following case we are indebted to Mr. Wise.

H. C- married, aged twenty-five, was admitted into Pepys ward, Oct. 9th, 1883. Three-quarters of an hour before admission the patient shot himself with a saloon pistol, the bullet being about the size of a pea. On admission, at two P.M., a small rounded wound over the right temple was found extending through the temporal muscle; there was no exit wound. The patient was conscious, and could answer questions; the pupils were very contracted; the face pale; extremities cold; pulse 72 , of good volume. There was frequent retching and vomiting. After he had been in the ward about a quarter of an hour, he became comatose with stertorous breathing. At 430 he was seen by Mr. Lawson, who, as the man was profoundly insensible, decided to enlarge the wound and examine the opening made in the skull by the bullet, to see if there was any depressed bone. This was done, and frag ments of bone were found pressing on the brain. A small portion of the adjacent bone was trephined, and two pieces of the inner table which were pressing on the brain were lifted away. Mr. Lawson then passed a probe along the track in the brain substance which the bullet had taken, but he did not succeed in feeling the bullet. No anæ:thetic was used, as the patient was in a state of deep insensibility, and did not even flinch during the operation. Soon after the operation he gradually recovered consciousness, and at about 11 o'clock he talked sensibly when spoken to, recognised his position, and when asked he stated that he had shot himself, and described the pistol with which he had done it. During the night he had no sleep, and there was frequent vomiting and retching, but no recurrence of insensibility.10th : This morning be is pale but quite rational ; retching, nausea, and sickness continue. Puptls are equal, small, and not acting readily to light. Tongue furred and flabby. Pulse 105, full but compressible. Complains of pain chiefly in occipital region. At the time he shot himself he was not the worse for liquor, though being a barman he often takes a considerable quantity of drink. Of late he has had much trouble, and has been at times apparently almost out of his mind, and has had attacks of intense pain at the back of the head. It was during one of these attacks that he shot himself.-11th : There is some twitching of facial muscles and tremulousness on protruding the tongue. On taking off the dressings the brain substance could be seen, through the wound, pulsating.-12th: Quite rational. Palse 108. The wound is looking well. Sleeps a good deal.-13tit: Pulse 88 , intermittent. Tongue coated all over with white fur ; sickness continues; does not seem to understand what is said to him. Temperature $986^{\circ}$ in axilla. - 14th : No sickness nor retching. - 15th: Pulse 81 , more regular. Tongue still furred and a little tremulous. There seems to be a little difficulty in articulating, he says his throat is "husky."-16th. The pulse this morning is slow and deliberate; the patient complains of more pain in the head referred especially to the trontal region, he appears more apathetic and comatose, and his condition altogether is not so good. There has been a little hæmorrhage during the night the wound was full of clots, all of which except the deeper ones were removed, and the wound dressed as usual with cold carbolic lotion. - 17th: Pulse 74; temperature 102.4 tongue still coated with white fur. He complains very much of headache. There has been some bæmorrhage from the wound during the night. Mr. Lawson this afternoon tied a small vessel. - 18th : The patient's condition since yesterday seems scarcely altered; no further hæmorrhage, -19th: He has loss of movement and sensation in the left arm and leg; he passes his urine uncontrolled; on the left side of the face the muscles are weak, although he is able to whistle feebly; the left orbicularis is very weak compared with the right the pupils are both dilated and acting to light, the right the more active. The wouna bled slightly on removing the dressings, and shows little disposition to heal; the brain seen through the opening has an unbealthy appearance.20th : During the night he had several fits of an epileptiform character; the right side of the face was drawn up ; bis breathing is now stertorous; pupils contracted, and not acting; is quite unconscious; tongue furred at tip, which is all that can be seen. Pulse 100 ; temperature $102.8^{\circ}$. Evening: pulse 160 ; temperature $1044^{\circ}$. - 21st: The fits continued the whole of yesterday. The temperature rose rapidly last evening, and the surface was covered with sweat. At $1 \mathrm{~A}$ M. the pulse was 180 . He died at $4 \mathrm{~A}$. Mr

Post-mortem Excmination. - Rigidity present; fairly nourished; moderate post-mortem congestion There was an oval wound one and three-quarters of an inch by an inch and a half in the right temporal region, situated an inch and three quarters above the right auditory meatus. In the centre of this wound there was an irregularly rounded aperture in the skull, the site of the trephine and bullet wound. The diameter of the trephine wound was half an inch; at one point where a portion of the original bullet wound was included, it measured three-quarters of an inch. There was no other wound in the skull. The edges of the wound were granulating slightly, but at its lower border a small sinus led to a collection of pus in the subcutaneous cellular tissue. On removing the calvarium the upper surface of the membranes over the right hemisphere was sen to be of a darker tint than that on the opposite side, and also more distended. Adherent to ${ }^{\circ}$ the edges of the wound in the dura mater there were two small pieces of bone completely separated; one was nearly as large as a three. penny piece, the other much smaller; a third piece, smaller still, was found in the track of the bullet, about a quarter of an inch within the brain. Seen from within, the wound ia the inner table was considerably larger than that in the outer. Brain : Both hemispheres were covered with a thick layer of adherent lympb, which on the right, side was brownish-red, from blood-staining, and on the left of a yellow tint. On scraping off this membrancus layer, the bullet-wound in the cortex of the brain was seen; it was situated in front of the fissure of Rolando, at the junction of the inferior and ascending frontal convolutions. The brain was then sliced from above downwards in situ. At a short distance from the surface a track of hæmorrhage was reached, extending from the external wound through the frontal lobe forwards and inwards. This measured three inches in its long diameter by one inch diameter transversely ; it consisted of black clot not adherent to the walls of the cavity. In its centre a small flattened bullet was found, weighing twelve grains. The hæmorrh?ge was situated wholly external to the corpus striatum or lateral ventricle. The edges of the cavity were soft and red; the lateral ventricles and other parts of the brain were normal.

Remarks.-This patient was an example of a gunshot wound of the skull, with the lodgment of the bullet in the brain, and death followed on the thirteenth day from acute suppurate meningitis. This injury is one of the most fatal of gunshot wounds. Even when the skull is penetrated, yet the bullet may not have entered the brain substance; it may be lodged in the wound, or be lying on the membranes without having penetrated them. A case of this kind was under my care in the Middlesex Hospital some years ogo, in which the patient had shot himself in the forehead. I trephined the skall at the seat of injury, and found the bullet lying on the membranes, and removed it. The patient recovered without a bad symptom. In the present 